\title{
Analysis of Drop Impact Behaviour of Eggs with Different Drop Height and Cushion Materials
}

\author{
Jianguo Zhang ${ }^{1}$, Fang Wang ${ }^{1 *}$, Shugang Yang ${ }^{1}$, YiNong Zhang ${ }^{1}$, Haiyan Song ${ }^{2}$, Maoting Li $^{1}$ \\ ${ }^{1}$ Department of Mechanical Engineering, Tianjin University of Science \\ and Technology, Tianjin, 300222, China \\ ${ }^{2}$ Department of Packaging \& Printing Engineering, Tianjin University of Science \& Technology, Tianjin, 300222, China
}

\begin{abstract}
In this study, the drop tests of eggs had been performed at different heights and different cushion materials, to assess the dynamic behaviour of eggs and to compare the cushioning performance of materials. Expandable polyethylene, expandable polystyrene and triple wall board were chosen as cushioning materials and the elastic modulus of materials were measured by the mechanical experiments. The impact locality was in the big end of egg. The impact acceleration and impact time were recorded by drop tester. The broken height and peak force were obtained for different cushion materials. The results showed that the larger elastic modulus of cushion materials, the greater impact force and less time, which was comparable to the discovery reported in the literature for similar materials.
\end{abstract}

Keywords-egg; drop test; impact height; impact force; cushioning materials.

\section{INTRODUCTION}

The demands for eggs are huge since they contain a high nutrient value. However, eggs are easy to be broken, resulting in considerable economic losses. Dynamic load during drop, collision and vibration is main cause of breakage of eggs. The dynamic behaviour of eggs was characterised by experimental methods. Eggshell crack was detected based on acoustic resonance frequency analysis with a non-destructive impact [1]. The mode shapes, the corresponding resonant frequencies and damping ratios of these modes were measured. The cushioning packaging is useful to cut down the damage of eggs in the circulation [2].Research shown that the elastic modulus of cushioning materials and drop height had close relations with impact force and impact time, however, the impact locality has no effect on the impact parameters [3].Crash test was developed to study the effect of egg shape index on damage area [4]. Recently, the computational simulations were developed for dynamic analysis of eggs [5]. The dynamic mechanical behaviour of the egg was simulated using the finite element (FE) method without regard to the interior fluid [6]. It was found that geometrical modifications (eggshell thickness, size of the egg) had a considerable influence on the fluid structure coupled natural frequencies. [7]. Applications of a combined computational fluid dynamics (CFD) in thermal processing of egg had been described in recently studies. Transient temperature and velocity profiles during thermal processes of egg shell bodies filled with a viscous liquid were studied [8]. Thermal pasteurization of a stationary egg is a time consuming process and this may lead to loss of various essential nutrients, denaturation of proteins and inactivation of enzymes present in the egg [9].

In present study, drop tests of eggs were done using the cushioning materials of expandable polyethylene, expandable polystyrene and triple wall board, to obtain the broken height and peak force and to compare cushioning performance of materials.

\section{MATERIALS AND METHODS}

It is difficult to identify the shape and size of an egg precisely because of its variation. The weight of the selected fresh eggs was close to $50 \mathrm{~g}$ and the egg shape index was close to 1.3 (the ratio of vertical diameter and lateral diameter). Cracked or irregularly shaped eggs were replaced after visual inspection.

The big end was chosen as the impact locality during drop test because the big end of an egg was easy to be broken. Expandable polyethylene (EPE), expandable polystyrene (EPS) and triple wall board were chosen as the cushioning materials and the thickness of the three materials was $48 \mathrm{~mm}$, $39 \mathrm{~mm}$ and $8 \mathrm{~mm}$ respectively.

The dropping tester, type 3356A24 acceleration sensor and analytical system of TEST PARTNER 3 were used to execute drop experimental work. The acceleration sensor was fixed on the end of long axis of the egg (fig.1). 

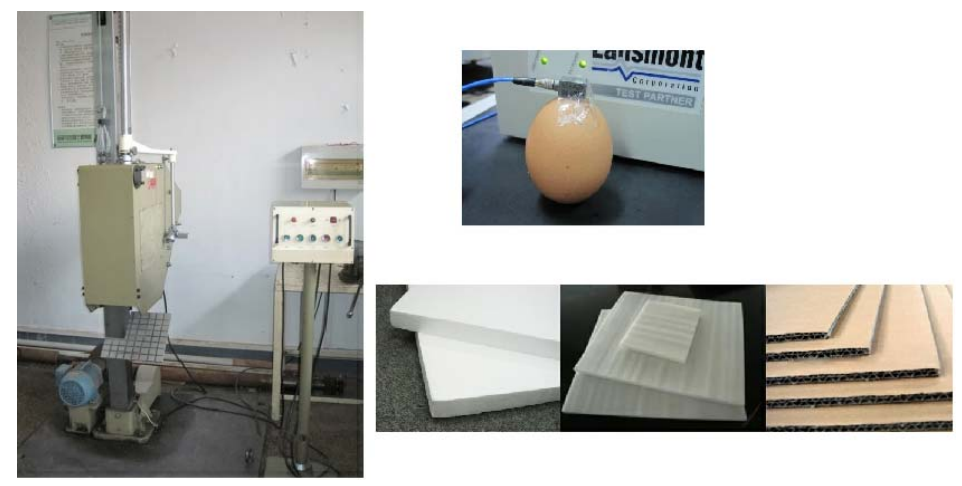

Figure 1. The drop test

The cushioning materials were cut into square with area of $50 \mathrm{~cm} \times 50 \mathrm{~cm}$. The mechanical properties of cushion materials were obtained by the mechanical experiment (fig.2). The elastic modulus was identified as $0.58 \mathrm{MPa}, 0.48 \mathrm{MPa}$ and $1.0 \mathrm{MPa}$ for each cushion materials separately.

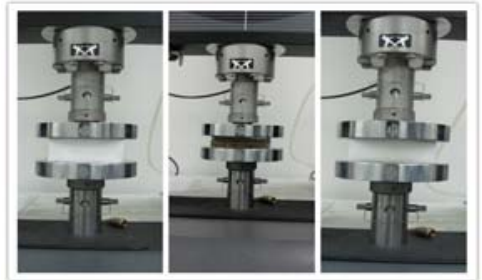

Figure 2 The mechanical experiment

\section{A. Test for determining broken height.}

The drop test was done with the started height of $5 \mathrm{~cm}$ and the incremental height was $5 \mathrm{~cm}$, to get the broken height for each cushioning material. Then the drop experiment was done below the broken height to observe the impact acceleration, impact force and impact time.

\section{B. Test for comparing cushioning materials.}

The same height with no damage was chosen for the drop test to analyze the property of cushioning material. The test was run 5 times for each cushioning material in chosen height.

\section{RESULTS AND DISCUSSION}

\section{A. Broken height.}

For the EPE cushioning material, no damage of eggshell was discovered in the height of $40 \mathrm{~cm}$. However, the eggs were partly broken with the drop height increasing from $40 \mathrm{~cm}$ to $50 \mathrm{~cm}$. The broken height of EPE cushioning material was determined to be between $40 \mathrm{~cm}$ and $45 \mathrm{~cm}$.

Similarly, the broken height of EPS cushioning material was between $35 \mathrm{~cm}$ and $40 \mathrm{~cm}$. For triple wall board cushioning material, eggshell should be damaged in the height between the $20 \mathrm{~cm}$ and $25 \mathrm{~cm}$.

From five tests, the averages of acceleration in the broken height was calculated, which was shown in fig.3.
According to the dynamics theory, impact force in the broken height was calculated from the acceleration, which was listed in table.1. It was shown that the value of force was between $40 \mathrm{~N}$ and $45 \mathrm{~N}$ with a destructive impact.

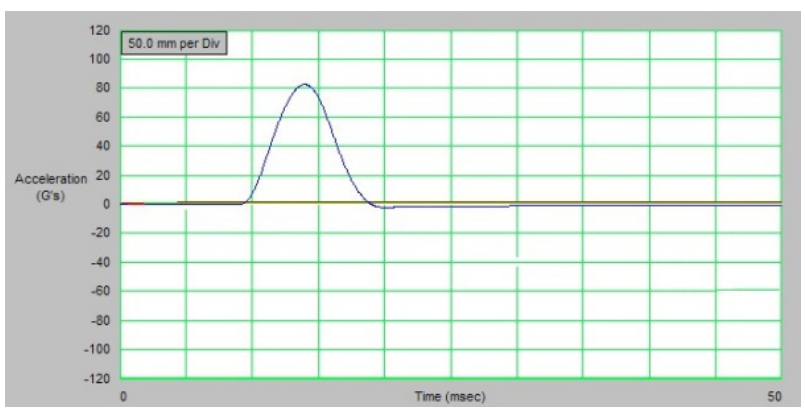

(a)

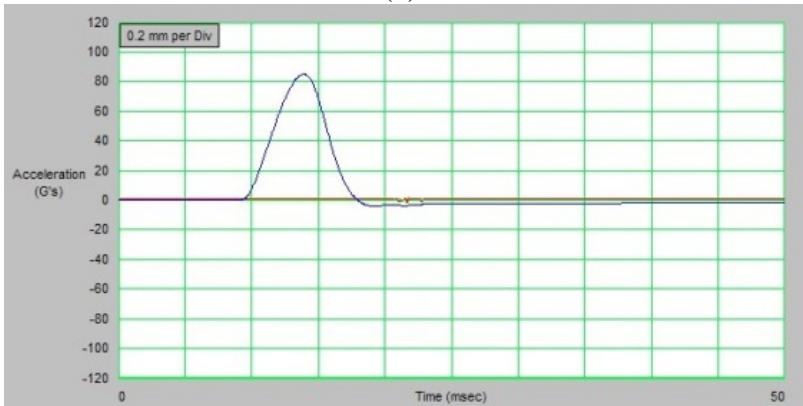

(b)

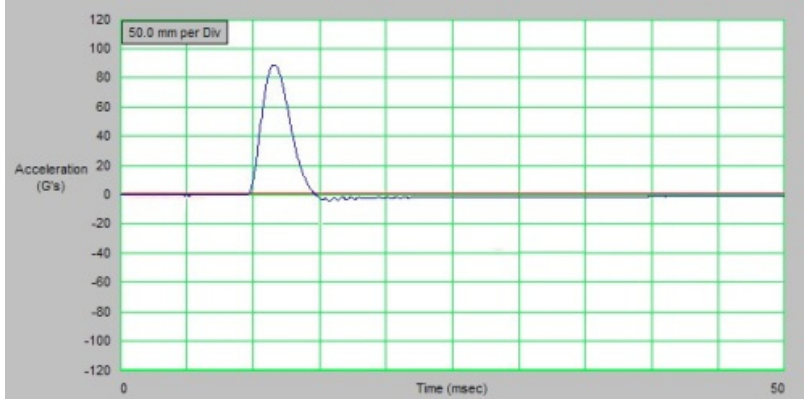

(c)

Figure 3. Acceleration curve from different cushioning materials (a) EPE with the height of $40 \mathrm{~cm}$, (b) EPS with the height of $35 \mathrm{~cm}$, (c) Triple wall board with the height of $20 \mathrm{~cm}$ 
TABLE I. DROP PARAMETERS IN THE BROKEN HEIGHT

\begin{tabular}{cccc}
\hline Material & Acceleration & $\begin{array}{c}\text { Impact } \\
\text { Force }\end{array}$ & $\begin{array}{c}\text { Impact } \\
\text { Time }\end{array}$ \\
\hline EPE & 82.49 & 40.42 & 8.05 \\
EPS & 84.89 & 41.59 & 7.15 \\
wall board & 88.82 & 43.52 & 4.1 \\
\hline
\end{tabular}

\section{B. Properties of cushioning materials}

The broken height of triple wall board cushioning material was lowest, that was $20 \mathrm{~cm}$. The heights of $10 \mathrm{~cm}, 15 \mathrm{~cm}$ and $20 \mathrm{~cm}$ were chosen for the drop tests. The history of acceleration was obtained to observe the cushioning properties of each cushioning material in the same height. Fig. 4 gave the acceleration curve in different heights.

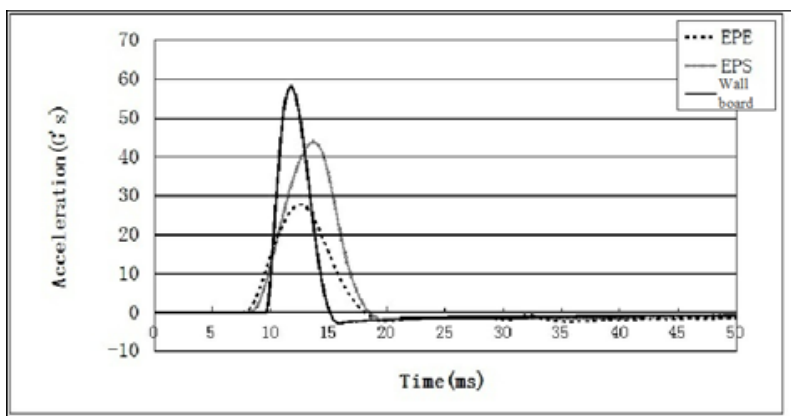

(a)

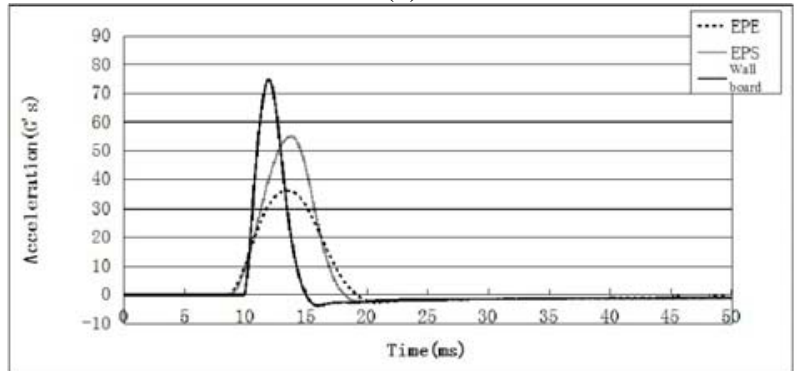

(b)

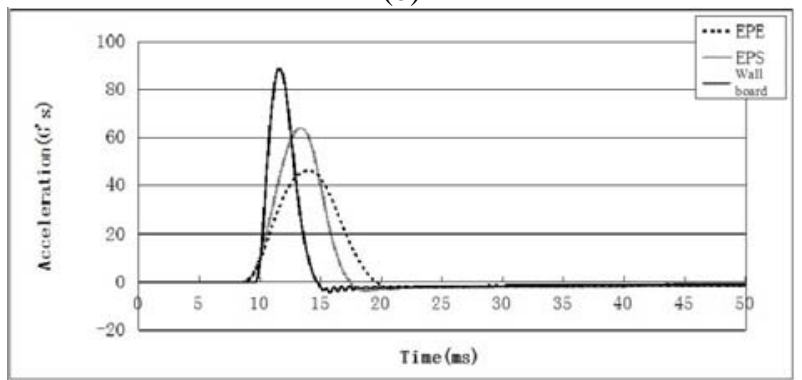

(c)

Figure 4. Impact acceleration and time from different cushion materials at the height with no damage. (a) $h=10 \mathrm{~cm}$, (b) $h=15 \mathrm{~cm}$, (c) $h=20 \mathrm{~cm}$

According to the dynamics theory, impact force of each cushioning material was calculated from the acceleration, which was listed in table.2. The impact time was shown in table.3.
TABLE II. DROP PEAK FORCE BASED ON DIFFERENT CUSHION MATERIAL

\begin{tabular}{cccc}
\hline Height $(\mathrm{cm})$ & EPE & EPS & wall board \\
\hline 10 & $13.60 \mathrm{~N}$ & $21.52 \mathrm{~N}$ & $28.48 \mathrm{~N}$ \\
15 & $17.69 \mathrm{~N}$ & $26.93 \mathrm{~N}$ & $36.68 \mathrm{~N}$ \\
20 & $22.72 \mathrm{~N}$ & $31.36 \mathrm{~N}$ & $43.52 \mathrm{~N}$ \\
\hline
\end{tabular}

TABLE III. IMPACT TIME BASED ON DIFFERENT CUSHION MATERIAL

\begin{tabular}{cccc}
\hline Height $(\mathrm{cm})$ & EPE & EPS & wall board \\
\hline 10 & $9.1 \mathrm{~ms}$ & $8.4 \mathrm{~ms}$ & $4.7 \mathrm{~ms}$ \\
15 & $8.7 \mathrm{~ms}$ & $7.7 \mathrm{~ms}$ & $4.2 \mathrm{~ms}$ \\
20 & $8.2 \mathrm{~ms}$ & $7.1 \mathrm{~ms}$ & $3.9 \mathrm{~ms}$ \\
\hline
\end{tabular}

For the three types of cushioning materials, the impact force increased and the impact time was reduced with the increased height.

The minimum value and maximum value of impact force were obtained from the cushioning material of EPE and triple wall board separately. The impact time from EPE cushioning material was longest and shortest time appeared in the triple wall board cushioning material in the same drop height .It was explained that the cushioning properties of EPE cushioning material was better than the EPS cushioning material and triple wall board cushioning material.

It was revealed that the drop height and features of cushioning material strongly affected the impact properties of eggshell.

\section{CONCLUSIONS}

A parametric analysis of the drop impact of chicken eggs had been carried out using drop experiments. The broken height of chosen cushioning materials and peak force of egg damage were determined. The impact height as well as the elastic modulus of cushioning materials strongly affected the values of impact force and time, which was comparable to the discovery reported in the literature for similar materials.

Further investigations should be carried out to study the dynamic behavior of the eggshell and the fluid loading of the inside fluid basing on computational simulations.

\section{ACKNOWLEDGEMENTS}

This work was financially supported by Tianjin University of Science and Technology Fund "Research on biomechanics of eggs based on fluid-structure interaction method” (Project No. 20120124).

\section{REFERENCES}

[1] De Ketelaere, B., Coucke, P., \& De Baerdemaeker, J., Eggshell crack detection based on acoustic resonance frequency analysis. Journal of Agricultural Engineering Research, 76, pp.157-163, 2000.

[2] Xinfang Liu, Shouyi Wu, Experimental analysis on mechanical properties of eggs.Journal of Jiangsu Institute of Technology, 13(1), pp.7-13, 1992.

[3] YuqiaoWang, Research on dropping impact characteristics of eggs. Master Thesis,WuHan, China: Huazhong Agricultural University, 2007. 
[4] Jinquan Chen, Research on the relationship between eggshell morphology and impact mechanical charaeteristies, Master Thesis, WuHan, China: Huazhong Agricultural University, 2011.

[5] Desmet, W., van Hal, B., Sas, P., \& Vandepitte, D., A computationally efficient prediction technique for the steadystate dynamic analysis of coupled vibro-acoustic systems. Advances in Engineering Software, 33, pp.527-540, 2002.

[6] Coucke, P., Assessment of some physical egg quality parameters based on vibrational analysis. PhD thesis, K.U.Leuven, Belgium, 1998.

[7] C. Perianu, B. De Ketelaere, B. Pluymers, W. Desmet, J, DeBaerdemaeker, E..DecuypereFinite element approach for simulating the dynamic mechanical behaviour of a chicken egg. Biosystems Engineering, 106, pp.79 -85, 2010.

[8] Com Denys, Jan G. Pieters, Koen Dewettinck, Computational fluid dynamics analysis of combined Siegfried conductive and convective heat transfer in model eggs. Journal of Food Engineering, 63, pp.281-290, 2004.

[9] Radhika Ramachandran, Deepti Malhotra, A. Anishaparvin, C. Anandharamakrishnan, Computational fluid dynamics simulation studies on pasteurization of egg in stationary and rotation modes. Innovative Food Science and Emerging Technologies, 12, pp.38-44, 2011. 